\title{
Development of a Mathematical Model to Calculate Accumulated Solid Waste: An Experiments and Statistical Sampling.
}

Taiwo Alare ( $\square$ alaretaiwopeter@gmail.com )

Federal University of Technology https://orcid.org/0000-0002-3939-9990

Kehinde Alare

Ladoke Akintola University of Technology

\section{Research Article}

Keywords: Waste management, solid waste collection, data collation, mathematical model

Posted Date: May 21st, 2021

DOl: https://doi.org/10.21203/rs.3.rs-393857/v1

License: (c) (i) This work is licensed under a Creative Commons Attribution 4.0 International License.

Read Full License 

Experimental and Statistical Sampling

4 Department Of Medicine, Ladoke Akintola University Of Technology, Ogbomosho ${ }^{2}$ \& Department

5 Of Mechanical Engineering, Federal University Of Technology, Akure ${ }^{1}$

6

7 Corresponding Author: Taiwo Alare

$8 \quad$ Email Address: alaretaiwopeter@gmail.com 


\subsection{Abstract}

In newest development, waste is being refined into a biofuel or recycled. Waste management has being an important factor in community development. The transformation of waste into useful materials has received much work. Therefore, database must be developed to know the amount of waste accumulated or generated over a given period of time. Taken into consideration the burning and recycle reduction factor, incremental factor and degradable waste ratio.

This paper look for a mathematical formula that can be used to generate data for amount of solid waste accumulated over time for geographical location in respect of mass.

Keywords: Waste management, solid waste collection, data collation, mathematical model

\subsection{Introduction}

Estimation has been given of waste generated in a geographical location per day (Alare, 2020). The formula works with the estimated figures of waste generated per day geographical location using statistical models sampling (Castle, 1993).

The importance of data in this present age cannot be overemphasized. It is important because it provide useful information for institutions, organizations and researchers of past record.

The aim of this research is to develop a formula that will help companies, institutions and researcher of biofuel, bioenergy system and other waste transformation related fields determine the amount of solid waste available to them in a geographical location based on the data derived from the formula and waste chart.

\subsection{Methods}

To determine the estimated accumulated waste of a geographical location for a given time interval. Three factors were considered and these factors varies from different geographical locations. Therefore, geographical locations should be experimental samples. The factors are:

Waste incremental ratio (i)

Degradable waste ratio (c)

Burning and recycle reduction factors

These factors tend reduce or increase the accumulated waste from expected waste generated. The availability of waste to waste companies can be examined using these 
factors. To determine these factors, statistical model and experimental sample methods will be employed.

\subsection{Statistical Model of Waste Incremental Ratio (i)}

$i=\frac{1}{t} \sum_{k=1}^{\infty}\left(\frac{N_{k}-N_{k}^{k}-1}{N_{k-1}}\right) i=\frac{1}{t} \sum_{k=1}^{\infty}\left(\frac{N_{k}-N_{k}-1}{N_{k-1}}\right)$ (Dass, 2008)

where, $N$ is amount of waste generated per

day and $k$ is the number of days

$t$ is number of days used which is $k_{\max }$

\subsubsection{Experimental Method Procedure}

Create an open boundary space samples of dumpsites A,B,C,D,E, .......

Determine the mass of solid waste of each samples

Check the increment in mass of each samples per day for given period of days

\begin{tabular}{|l|l|l|l|}
\hline Sample & Day1 & Day2 & $\begin{array}{l}\text { Day3 } \ldots \ldots \ldots \ldots \\
\text { Day k }\end{array}$ \\
\hline $\mathrm{A}$ & $N_{1} a$ & $N_{2} a$ & $N_{3} a$ \\
$\mathrm{~B}$ & $N_{1} b$ & $N_{2} b$ & $N_{3} a \ldots \ldots \ldots \ldots$ \\
$\mathrm{C}$ & $N_{1} c$ & $N_{2} c$ & $N_{k} a N_{k} a$ \\
$\mathrm{D}$ & $N_{1} d$ & $N_{2} d$ & $N_{3} b$ \\
$\mathrm{E}$ & $N_{1} e$ & $N_{2} e$ & $N_{3} b \ldots \ldots \ldots \ldots$ \\
. &. &. & $N_{k} b N_{k} b$ \\
. &. &. & $N_{3} c$ \\
. &. &. & $N_{3} c \ldots \ldots \ldots \ldots$ \\
. &. &. & $N_{k} c N_{k} c$ \\
$\infty$ & $N_{1} \infty$ & $N_{2} \infty$ & $N_{3} d$ \\
& & & $N_{3} d \ldots \ldots \ldots \ldots$ \\
& & & $N_{k} d N_{k} d$ \\
& & & $N_{3} e$ \\
& & & $N_{3} e \ldots \ldots \ldots \ldots . . .$. \\
& & & $N_{k} e N_{k} e$ \\
& & &. \\
\hline
\end{tabular}




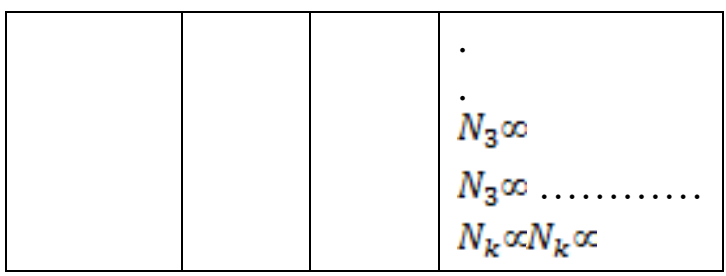

Waste incremental ratio for each samples

$$
\begin{aligned}
& i_{A}=\frac{1}{t} \sum_{k=1}^{\infty} \frac{N_{k a}-N_{(k-1) a}}{N_{k a}} i_{A}=\frac{1}{t} \sum_{k=1}^{\infty} \frac{N_{k a}-N_{(k-1) a}}{N_{k a}} \\
& i_{B}=\frac{1}{t} \sum_{k=1}^{\infty} \frac{N_{k b}-N_{(k k-1) b}}{N_{k} b} i_{B}=\frac{1}{t} \sum_{k=1}^{\infty} \frac{N_{k b}-N_{(k k-1) b}}{N_{k} b} \\
& i_{C}=\frac{1}{t} \sum_{k=1}^{\infty} \frac{N_{k c}-N_{(k k-1) e}}{N_{k c}} i_{C}=\frac{1}{t} \sum_{k=1}^{\infty} \frac{N_{k c}-N_{(k k-1) e}}{N_{k c}} \\
& i_{D}=\frac{1}{t} \sum_{k=1}^{\infty} \frac{N_{k d}-N_{(k k-1) d}}{N_{k d}} i_{D}=\frac{1}{t} \sum_{k=1}^{\infty} \frac{N_{k d}-N_{(k-1) d}}{N_{k d}} \\
& i_{E}=\frac{1}{t} \sum_{k=1}^{\infty} \frac{N_{k \varepsilon}-N_{(k-1))}}{N_{k \varepsilon}} i_{E}=\frac{1}{t} \sum_{k=1}^{\infty} \frac{N_{k \varepsilon}-N_{(k-1)]}}{N_{k e}} \\
& i_{\infty}=\frac{1}{t} \sum_{k=\infty}^{\infty} \frac{N_{k \infty \infty}-N_{(k-1) x}}{N_{k \infty \infty}} i_{\infty}=\frac{1}{t} \sum_{k=\infty}^{\infty} \frac{N_{k \infty \infty}-N_{(k-1) x}}{N_{k \infty \infty}}
\end{aligned}
$$

\subsection{Average waste incremental ratio}

$$
i=\frac{\sum_{k=}^{w} A_{k}^{i}}{\text { number of samples }} i=\frac{\sum_{k=A^{i}}^{w}}{\text { number of samples }}
$$

In order to avoid or minimize mathematical and computational error, a small number of samples and minimum duration of days is advice.

\subsection{Statistical Model of Degradable Waste Ratio (c)}

$c=\frac{1}{t} \sum_{k=1}^{\infty}\left(\frac{N_{k}-N_{k}+1}{(k+1)-k}\right) c=\frac{1}{t} \sum_{k=1}^{\infty}\left(\frac{N_{k}-N_{k}+1}{(k+1)-k}\right)$

where, $N$ is amount of waste generated per day and where, $N$ is amount of waste generated per day and

$k$ is the number of days

$t$ is the number of month of experiment 


\subsubsection{Experimental Method Procedure}

Create space samples of dumpsite $\mathrm{A}, \mathrm{B}, \mathrm{C}, \mathrm{D}, \mathrm{E}, \ldots \ldots \ldots \infty$ in a closed and isolated system

Determine the mass of solid waste of each samples

Check the decrement in mass of each samples per day for given period of days

\begin{tabular}{|c|c|c|c|}
\hline Sample & $\begin{array}{l}\text { Month } \\
1\end{array}$ & $\begin{array}{l}\text { Month } \\
2\end{array}$ & $\begin{array}{l}\text { Month .........Month } \\
3 \ldots \ldots \ldots \ldots \ldots \ldots k\end{array}$ \\
\hline A & $N_{1} a$ & $\mathrm{~N}_{2} \mathrm{a}$ & $N_{3} a N_{3} a \ldots \ldots \ldots \ldots \ldots$ \\
\hline B & $N_{1} b$ & $\mathrm{~N}_{2} b$ & $N_{k} a N_{k} a$ \\
\hline $\mathrm{C}$ & $N_{1} c$ & $\mathrm{~N}_{2} \mathrm{C}$ & $N_{3} b N_{3} b$ \\
\hline $\mathrm{D}$ & $N_{1} d$ & $\mathrm{~N}_{2} d$ & $N_{k} b N_{k} b$ \\
\hline $\mathrm{E}$ & $N_{1} e$ & $\mathrm{~N}_{2} e$ & $N_{3} c N_{3} c \ldots$ \\
\hline$\cdot$ & . & . & $N_{k} c N_{k} c$ \\
\hline$\cdot$ & $\cdot$ & $\cdot$ & $N_{3} d N_{3} d \ldots \ldots$ \\
\hline . & $\cdot$ & & $N_{k} d N_{k} d$ \\
\hline$\infty$ & $N_{1} \infty$ & $\mathrm{N}_{2} \infty$ & $N_{3} e N_{3} e \ldots \ldots$ \\
\hline & & & $N_{k} e N_{k} e$ \\
\hline & & & \\
\hline & & & \\
\hline & & & $\mathrm{N}_{3} \propto \mathrm{N}_{3} \infty$ \\
\hline & & & $N_{k} \propto N_{k} \propto$ \\
\hline
\end{tabular}

Waste incremental ratio for each samples

$$
\begin{aligned}
& c_{A}=\frac{1}{t} \sum_{k=1}^{\infty} \frac{N_{k a}-N_{(k+1) a}}{((k+1)-k) a} c_{A}=\frac{1}{t} \sum_{k=1}^{\infty} \frac{N_{k a}-N_{(k+1) a}}{((k+1)-k) a} \\
& c_{B}=\frac{1}{t} \sum_{k=1}^{\infty} \frac{N_{k b}-N_{(k+1) b}}{((k+1)-k) b} c_{B}=\frac{1}{t} \sum_{k=1}^{\infty} \frac{N_{k b}-N_{(k+1) b}}{((k+1)-k) b} \\
& c_{C}=\frac{1}{t} \sum_{k=1}^{\infty} \frac{N_{k e}-N_{(k+1) e}}{((k+1)-k) c} c_{C}=\frac{1}{t} \sum_{k=1}^{\infty} \frac{N_{k e}-N_{(k+1) c}}{((k+1)-k) e} \\
& c_{D}=\sum_{k=1}^{\infty} \frac{N_{k d}-N_{(k+1) a}}{((k+1)-k) d} c_{D}=\sum_{k=1}^{\infty} \frac{N_{k d}-N_{(k+1) d}}{((k+1)-k) d} \\
& c_{E}=\frac{1}{t} \sum_{k=1}^{\infty} \frac{N_{k \varepsilon}-N_{(k+1) e}}{((k+1)-k) e} c_{E}=\frac{1}{t} \sum_{k=1}^{\infty} \frac{N_{k e}-N_{(k+1) e}}{((k+1)-k) e}
\end{aligned}
$$


$c_{\infty}=\frac{1}{t} \sum_{k=\infty}^{\infty} \frac{N_{k x \infty}-N_{(k+1) x}}{((k+1)-k) \infty} c_{\infty}=\frac{1}{t} \sum_{k=\infty}^{\infty} \frac{N_{k \infty \infty}-N_{(k+1) x}}{((k+1)-k)_{\infty}}$

Note

$((k+1)-k)=$

30 days $k$ should be in days

$((k+1)-k)=$

30 days $k$ should be in days

\section{2.2 Average waste degradable ratio}

$$
c=\frac{\sum_{\tilde{k}=A^{c_{k}}}^{c}}{\text { number of samples }} c=\frac{\sum_{k}^{w}=A^{c_{k}}}{\text { number of samples }}
$$

\section{3Burning and Recycle Factor}

The assumed burning factor is in the range of 0.005 to 0.006 depending on the burning and recycling activities of the geographical area considered.

\subsection{Result}

A reduction constant $\mathrm{k}$ is developed from the mathematical combination of all the factors ensuring that reduction is at a reasonable range.

$k=i^{b c} k=i^{b c}$

The amount of solid waste accumulated over a given period in term of the mass is given as

$M=k T N+N M=k T N+N$

$\mathrm{T}=\mathrm{T}_{0}-1$

Where

$\mathrm{M}$ is accumulated waste over a period of time

$\mathrm{K}$ is reduction constant

$\mathrm{T}_{0}$ is period of time taken in days 


\section{Conclusion}

This paper has shown a method of calculating the amount of accumulated solid waste in mass. The factors consider varies from one geographical area to another. We employ researchers to further the research. with the aim of obtaining the factors for different geographical locations in the world. Develop a chart that will contain the data of all i, c and $\mathrm{k}$ for all experimented geographical area.

\subsection{Reference}

Castle, G. (1993). huazordous waste facility siting in manitoba-Case study of a success. Journal of the Air and Waste Management Association.

Dass, H. (2008). Advance Engineering Mathematicals. New Delhi: S. Chand.

Alare K, Alare T., Ojelola K., Akinnawo O. (2020). Smart and Clean Environment: An Importance Qualification of a Smart City (ecosystem engineering). Alare's Research Institute Anual Conference. Retrieve from: http://dx.doi.org/10.13140/RG.2.2.35939.27684 